\title{
Patryk Danielewicz
}

\section{Pojęcie \\ „kultury politycznej” \\ w wybranych \\ współczesnych \\ teoriach politologicznych \\ a perspektywa \\ filozofii polityki \\ DOI $10.35757 /$ CIV.2016.18.04}

\section{Wprowadzenie}

Główny cel artykułu stanowi próbę odpowiedzi na pytanie, co mamy na myśli, kiedy mówimy o kulturze politycznej. Nie jest to bynajmniej zadanie proste i niniejsza praca nie rości sobie pretensji, aby ująć problem w sposób pełny i wyczerpujący, gdyż definicji tego pojęcia powstało wiele i przyjmowały różnoraką formułę. Dlatego skupię się jedynie na wybranych koncepcjach, które powstały na gruncie współczesnych teorii politologicznych, by następnie zestawić je $z$ perspektywa filozofi i politycznej. Zaproponowane ujęcia nie sa być może najbardziej reprezentatywnymi czy popularnymi defi nicjami, sa jednak istotne ze względu na zawarte w nich próby

Patryk Danielewicz - absolwent filozofii oraz Wydziału Stosowanych Nauk Społecznych Uniwersytetu Warszawskiego. 
przekształcenia terminu „kultury politycznej” w empiryczne narzędzie, pozwalajace dostosować je do rzeczywistości politycznej. Słowo „próby” nie jest tutaj przypadkowe, gdyż - jak zwracaja uwage badacze, których poglądy zostana w niniejszym tekście przytoczone - nie jest to zadanie łatwe, a może nawet nie w pełni możliwe. Dla kontrastu zostało też przedstawione ujęcie filozoficzne, które - w przeciwieństwie do perspektywy politologicznej - nie musi podlegać empirycznej weryfikacji. To, co dla filozofii politycznej wydaje się interesujące, to kontrfaktyczne ujęcie rzeczywistości. Kultura polityczna przybiera tu postać idei.

Punktem wyjścia dla rozważań uczyńmy klasyczną definicje „kultury politycznej”, czyli pierwsze ujęcie tego terminu, które zaproponował Gabriel Almond i współpracujący z nim uczeni. Następnie zostana przedstawione współczesne definicje, kolejno: Władysława Markiewicza, Andrzeja W. Jabłońskiego oraz Zbigniewa Bloka, by na koniec przytoczyć określenie powstałe na gruncie filozofii politycznej, które zaproponowali Cezary Kościelniak i Janusz Wiśniewski.

$\mathrm{Z}$ zestawienia zaproponowanych definicji nie wyłania się jednolite ujęcie kultury politycznej. Niemniej w odpowiedzi na zadane we wstępie pytanie nie chodzi o przedstawienie syntezy obecnych już w literaturze definicji czy o faworyzowanie jednej $z$ propozycji, lecz o zarysowanie pewnego pola refleksji, w którym to pojęcie występuje. Warto tu zauważyć, że mimo znaczących różnic między zaprezentowanymi perspektywami, można dla nich wydobyć wspólny trzon definicyjny, czyli pewne punkty przez przywoływanych badaczy podzielane. Rzecz jednak w tym, aby owego pojęcia nie redukować do wspólnej podstawy, ale by właśnie ujać je w całej różnorodności.

\section{Klasyczna definicja kultury politycznej}

Termin „kultura polityczna” wywodzi się z politologii i został wprowadzony przez Gabriela Almonda w latach pięćdziesiątych 
XX wieku. Zdefiniował on to pojęcie jako „określony układ postaw politycznych, odczuć, informacji i umiejętności”" Można zatem powiedzieć, że na kulturę polityczna składaja się wartości, przekonania, oceny i wzory ustosunkowania się do polityki oraz do systemu politycznego. Prezentowana definicja była przez autora znaczaco doprecyzowana w kolejnych jego badaniach i pracach. W artykule Kultura polityczna, napisanym wraz z Binghamem G. Powellem, autorzy pisza, iż kultura polityczna to:

całokształt indywidualnych postaw i orientacji politycznych uczestników danego systemu. Jest to sfera subiektywna, leżąca u podstaw działań politycznych, nadajacca im znaczenia. Owe indywidualne orientacje nosza w sobie kilka składników, a mianowicie (a) orientację poznawcza - prawdziwa lub fałszywa wiedzę o obiektach i ideach politycznych, (b) orientacje afektywna - poczucie więzi, zaangażowanie, sprzeciw wobec obiektów politycznych, (c) orientację oceniajaca - sądy i opinie o obiektach politycznych ${ }^{2}$.

Cezary Kościelniak i Janusz Wiśniewski w tekście Kultura polityczna $w$ perspektywie filozofii politycznej zwracaja uwage na dwa fundamenty tej definicji: „subiektywny stosunek do rzeczywistości politycznej oraz na obiekty polityczne"3, które będa później nazwane przez Almonda i Powella obiektami orientacji politycznej i określane następująco:

Obiektami orientacji politycznej są: system polityczny jako całość, poszczególne role i struktury polityczne, indywidualni lub grupowi wykonawcy oraz $[\ldots]$ decyzje publiczne. Kategoria ta obejmuje również wszystkich aktorów gry politycznej ${ }^{4}$.

\footnotetext{
1 A. Jabłoński: Kultura polityczna i jej przemiany, w: A. Jabłoński, L. Sobkowiak (red.): Studia z teorii polityki, t. 2, Wydawnictwo Uniwersytetu Wrocławskiego, Warszawa 1998, s. 178.

2 G. Almond, B.G. Powell: Kultura polityczna, przekład W. Kalinowski, w: W. Derczyński, A. Jasińska-Kania (red.): Elementy teorii socjologicznych. Materiały do dziejów współczesnej socjologii zachodniej, Państwowe Wydawnictwo Naukowe, Warszawa 1975, s. 578.

3 C. Kościelniak, J. Wiśniewski: Kultura polityczna $w$ perspektywie filozofii politycznej, w: Z. Blok (red.): Teoretyczne i metodologiczne problemy badań nad kultura polityczna, Wydawnictwo Naukowe Wydziału Nauk Politycznych i Dziennikarstwa UAM, Warszawa 2005, s. 35.

4 G. Almond, B. G. Powell: Kultura polityczna, s. 579.
} 
W skrócie definicję kultury politycznej przedstawiona przez Almonda i Powella można ująć jako postawę jednostki względem obiektów orientacji politycznej, a więc jako konglomerat wiedzy, jaka jednostka posiada o obiektach politycznych, emocjonalnego stosunku do nich oraz ocen i sadów na ich temat. Warto zwrócić uwage na to, że w systemach demokratycznych obiektem orientacji politycznej staje się sama jednostka jako podmiot polityczny - odnosić się więc będzie także sama do siebie. Powyższe określenie dalej nazywać będę klasyczna definicją kultury politycznej i będzie ono stanowić punkt odniesienia względem kolejnych prób definiowania pojęcia „kultura polityczna”.

\section{Typologie kultur politycznych}

$\mathrm{Na}$ podstawie tak skonstruowanej definicji oraz przeprowadzonych badań empirycznych Almond $z$ kolejnym badaczem, Sidneyem Verba, wyróżnili trzy „czyste” typy kultury politycznej:

1. Zaściankowa kultura polityczna. Jak zwracaja uwage ci badacze, w społeczeństwach, w których ten typ kultury dominuje, nie ma wyspecjalizowanych ról politycznych: funkcje wodzów, naczelników czy szamanów łączą w sobie zadania o charakterze politycznym, ekonomicznym i religijnym. Co więcej, postawa członków takich społeczności względem polityki nie jest odrębna od ich stosunku do spraw społecznych czy religijnych. Charakteryzuja ja znikome oczekiwania na zmiany $\mathrm{w}$ obrębie systemu politycznego ${ }^{5}$, brak wiedzy o polityce oraz brak zainteresowania sprawami życia publicznego. Władza polityczna jest skupiona w rękach elit, a rzadzeni nie mają żadnej możliwości wpływu na decyzje publiczne ${ }^{6}$.

\footnotetext{
5 G. Almond, S. Verba: The Civic Culture. Political Attitudes and Democracy in Five Nations, Little, Brown, Boston 1965, cyt. za: [omówieniem rozdziału An Aproach to Political Culture w:] J. Szczupaczyński (red.): Władza i społeczeństwo. Antologia tekstów z zakresu socjologii polityki, Wydawnictwo Naukowe Scholar, Warszawa 1995, s. 334.

${ }_{6}$ A. Jabłoński: Kultura polityczna i jej przemiany, w: A. Jabłoński, L. Sobkowiak (red.): Studia $z$ teorii polityki, t. 2, s. 108.
} 
Przykładami takich społeczności sa afrykańskie społeczności plemienne czy też scentralizowane księstwa i królestwa Afryki ${ }^{7}$.

2. Kultura polityczna podporzadkowania. Charakteryzuje ją wyrazista postawa względem całego systemu, ale rzadko wobec jednostki jako podmiotu politycznego. Społeczeństwo ma świadomość istnienia władzy rządowej oraz ma do niej stosunek afektywny, przy czym władza ta jest ujmowana tutaj jako całość zasadniczo odrębna od jednostek ${ }^{8}$. Członkowie społeczeństwa maja prawo do uczestnictwa $\mathrm{w}$ działalności politycznej, ale $z$ niego nie korzystają. Najczęściej więc przyjmuja postawę obserwatora, a sama polityka nie stanowi dla nich sfery aktywności życiowej. Ten typ kultury politycznej funkcjonuje zarówno w społeczeństwach tradycyjnych, jak i w nowoczesnych demokracjach przemysłowych ${ }^{9}$.

3. Kultura polityczna uczestnictwa. W tym typie kultury politycznej jednostki w społeczeństwie dążą do jak największej wiedzy o systemie politycznym, zarówno jako całości, jak i o poszczególnych jej częściach. Członkowie tej kultury politycznej przyjmuja wyraziste postawy względem różnych obiektów politycznych, w tym między innymi co do aktywnej roli jednostki w systemie ${ }^{10}$. Kultura polityczna uczestnictwa jest charakterystyczna dla demokracji, w których większość obywateli partycypuje w życiu publicznym na różnych jego poziomach ${ }^{11}$.

Poza wyżej wymienionymi „czystymi” typami kultury politycznej wspomniani autorzy wskazują także typy pośrednie, między innymi, takie jak: kultura partycypacyjno-poddańcza, partycypacyjno-zaściankowa czy poddańczo-zaściankowa. Najwięcej uwagi poświęcaja jednak kulturze obywatelskiej, która jest połączeniem kultur partycypacyjnej oraz poddańczej. Istota tego modelu jest „umiarkowany (nie nadmiernie duży) zakres uczestnictwa w systemie

\footnotetext{
7 G. Almond, S. Verba: The Civic Culture. Political Attitudes and Democracy in Five Nations, Little, Brown, Boston 1965, s. 334.

8 G. Almond, S. Verba: The Civic Culture, s. 335.

9 A. Jabłoński: Kultura polityczna i jej przemiany, s. 180.

${ }^{10}$ G. Almond, S. Verba: The Civic Culture, s. 335.

${ }^{11}$ A. Jabłoński: Kultura polityczna i jej przemiany, s. 180.
} 
rządów oraz znaczny zakres świadomego, biernego przyzwolenia obywateli do sprawowania władzy w ich imieniu przez demokratycznie wybrane elity" ${ }^{\prime 2}$. Kultura obywatelska zatem niejako $z$ definicji odnosi się do państw demokratycznych. Obywatele akceptuja reguły gry politycznej, charakterystyczne dla demokracji, sa zaangażowani w sprawy publiczne, maja dużą wiedzę o systemach politycznych oraz darza zaufaniem instytucje władzy państwowej ${ }^{13}$. Ten typ kultury politycznej jest przez autorów oceniany pozytywnie. Niemniej, choć uznali oni, że kultura obywatelska stanowi niezbędny składnik państw demokratycznych, to jednak nie określili dokładnie kryteriów kulturowych, które byłyby niezbędne do zaistnienia stabilnej demokracji ${ }^{14}$.

\section{Współczesne politologiczne ujęcia kultury politycznej}

Współcześni badacze kultury politycznej zwracaja uwagę, że jej ujęcie klasyczne w obecnych realiach jest mało użyteczne dla badań empirycznych ${ }^{15}$. Zaproponowana przez Almonda i Verbę typologia nie daje dokładnego i zróżnicowanego obrazu społeczeństw w kwestiach polityki. Trzeba także uważać, aby pojęcie to nie było utożsamiane $z$ takimi terminami, jak „polityka”, „system polityczny” czy „życie polityczne”16. Jednocześnie badacze sa zgodni w kwestii użyteczności samego terminu dla rozważań oraz badań empirycznych ${ }^{17}$, dlatego też próbuja ponownie powołać je do życia. Na kolejnych stronach niniejszego artykułu skupię się na kilku propozycjach nowego ujęcia kultury politycznej, które - według ich twórców - lepiej oddają złożoność współczesnych społeczeństw.

12 Ibidem.

13 Ibidem, s. 181.

14 Ibidem.

${ }^{15}$ Z. Blok: Czynniki determinujące kulture polityczna oraz modele kultury politycznej, w: idem: Teoretyczne i metodologiczne..., s. 45.

${ }^{16}$ Ibidem, s. 52.

${ }_{17}$ Ibidem, s. 45. 


\section{Ujęcie Władysława Markiewicza}

Władysław Markiewicz proponuje, aby pojęcie „kultura polityczna" rozumieć dużo szerzej niż Almond i współpracujący z nim badacze. Sugeruje bowiem, aby rozumieć „kulturę polityczną” jako:

[...] historycznie ukształtowane elementy $\mathrm{w}$ globalnie pojętej kulturze, które dotyczą wartości uznawanych i pożądanych przez dana zbiorowość odnoszących sie przede wszystkim [...] do systemu władzy państwowej. Należą do niej zatem także kryteria, według których społeczeństwo zwykło oceniać politykę państwa i solidaryzować się lub przeciwstawiać się kierunkom działania władzy [...]. Znamieniem kultury politycznej jest miejsce wyznaczone polityce $\mathrm{w}$ przyjętej przez dana zbiorowość hierarchii wartości oraz $\mathrm{w}$ przejawiającym się $\mathrm{w}$ określonych postawach i zachowaniach stosunku danej zbiorowości do różnych instytucji publicznych i form działalności politycznej [...] wyrażającym się przede wszystkim $\mathrm{w}$ dobrowolnym uczestnictwie w pracach instytucji politycznych ${ }^{18}$.

Do istoty tak zdefiniowanej kultury politycznej będą należeć między innymi: „świadomość historyczna, zachowania i postawy polityczne, przywództwo polityczne, reguły gry politycznej, zasady pedagogiki politycznej"19 Widać tutaj pewne rozszerzenie koncepcji Almonda. Markiewicz zachowuje w swoim ujęciu trzon klasycznej definicji, jakim sa postawy i zachowanie polityczne, lecz jednocześnie rozszerza ją o świadomość, reguły i zasady kultury politycznej ${ }^{20}$. Dodanie tych elementów zasadniczo komplikuje możliwość prostej typizacji, co jednocześnie pozwala na bardziej zróżnicowane wyobrażenie społeczeństw. Słabą strona tak szerokiej definicji jest trudność w stworzeniu odpowiedniego empirycznego narzędzia, które pozwalałoby na zbadanie tak ujętej kultury ${ }^{21}$. Aby pojęcie kultury politycznej było użyteczne, musi być osadzone jak najbliżej rzeczywistości empirycznej, gdyż tylko w taki sposób można uzyskać dodatkowa wiedzę o świecie.

\footnotetext{
${ }^{18}$ W. Markiewicz: Kultura polityczna jako przedmiot badań naukowych, „Kultura i Społeczeństwo" 1976, nr 4, s. 28, cyt. za: Z. Blok: Czynniki determinujace..., s. 48.

${ }^{19}$ Z. Blok: Czynniki determinujące...

${ }^{20}$ Ibidem.

${ }^{21}$ Ibidem.
} 


\section{Ujęcie Andrzeja W. Jabłońskiego}

Zupełnie inne podejście do problemu prezentuje Andrzej W. Jabłoński. Nie proponuje on własnej definicji kultury politycznej, zwraca jednak uwage, że definicja zaproponowana przez Almonda jest nazbyt ogólna. Sam proponuje swobodniejsze podejście do tej kwestii i zamiast wskazywać na twarde i ogólne wyznaczniki, postuluje, aby mówić o „pewnych cechach kulturowych społeczeństw, sprzyjających bądź niesprzyjających demokracji”22. Widać tutaj, że autor redukuje analizowane pojęcie do pojęcia kultury obywatelskiej - konglomeratu kultury uczestnictwa i podporządkowania - która według klasycznych rozważań miała być najkorzystniejszym typem kultury dla państw demokratycznych. Jak zwróciłem już uwage wyżej, Almond i Verba nie mówią, jakie proporcje połączenia tych dwóch kultur są optymalne dla kultury obywatelskiej. Rozwiazanie tego problemu staje się celem dla Jabłońskiego i zarazem jego pomysłem na typizację kultur politycznych. Nie proponuje on wyodrębnienia „czystych” typów kultury politycznej. Dla niego kultura polityczna jest wartościa na osi pomiędzy dwoma skrajnymi systemami politycznymi: demokracja i autorytaryzmem. Wyznaczanie tej wartości dokonuje się przez nałożenie na siebie punktów na trzech osiach, rozpościerających się pomiędzy skrajnymi cechami kulturowymi społeczeństw. Inaczej mówiąc, o pozycji danego społeczeństwa między demokracją a autorytaryzmem będzie decydować jego stosunek względem sześciu wartości, ułożonych w trzy binarne opozycje: indywidualizm - kolektywizm, elityzm - egalitaryzm, racjonalizacja konfliktu - nietolerancja.

\section{Indywidualizm - kolektywizm}

Postawa indywidualistyczna charakteryzuje się uznaniem prymatu dobra prywatnego nad dobrem publicznym oraz faworyzo-

${ }^{22}$ A. Jabłoński: Kultura polityczna i jej przemiany, s. 186. 
waniem rynkowego systemu ekonomicznego i politycznego. Przyjmujący taka postawę oczekują od państwa minimalnej ingerencji w życie społeczne oraz gospodarcze. Jednostkom takim właściwe jest poczucie wyzwolenia $z$ więzi społecznych i identyfikacji grupowej, co pozwala im na dokonywanie wyborów życiowych zgodnie $z$ ich indywidualnymi motywacjami i kryteriami ocen. Przeciwieństwem tej postawy jest kolektywizm, charakteryzujacy się silnym przestrzeganiem przez jednostkę norm grupowych oraz przywiązaniem do tradycji, rodziny i religii. Jednostka o nastawieniu indywidualistycznym wyżej będzie ceniła wolność niż równośćc ${ }^{23}$.

\section{Elityzm - egalitaryzm}

Elitystyczna postawa cechuje się szacunkiem dla władzy oraz uznaniem jej aktywności na polach gospodarki i życia społecznego. W kulturze politycznej, w której przeważa takie podejście, jednostki uznaja elity za odpowiednią grupę do pełnienia funkcji politycznych i roli przywódczej w społeczeństwie. Na drugim biegunie została umiejscowiona postawa egalitarna charakteryzujaca się respektem względem idei równości członków społeczeństwa, tym samym przy odrzuceniu poglądu, w którym jednostki lepiej urodzone, o większym kapitale ekonomicznym lub kulturowym sa bardziej odpowiedzialne za sprawy polityczne kraju, a co za tym idzie - lepiej przygotowane do zarządzania państwem ${ }^{24}$.

\section{Racjonalizacja konfliktu - nietolerancja}

Postawa, która dąży do racjonalizacji konfliktu, charakteryzuje się poszukiwaniem metod służących kompromisowi i instytucjonalizacji. Konflikt jest niejako wpisany we wszystkie społeczeństwa, dlatego też należy powołać szereg instytucji, których celem będzie szukanie rozwiązań najbardziej racjonalnych, zadowalających możliwie jak największą część społeczeństwa. Przykładami

${ }^{23}$ Ibidem, s. 182.

${ }^{24}$ Ibidem, s. 183. 
dążności do racjonalizacji konfliktu moga być brytyjski system parlamentarny lub francuski system republikański. Przeciwieństwem tej postawy jest nietolerancja wobec ludzi, którzy myśla inaczej. Gdy w danym społeczeństwie brak tolerancji spotka się $z$ aprobata, wówczas konflikty będą rozwiązywane przez eliminację jednej ze stron za pomoca wszelkich dostępnych metod, jakimi dysponuje władza polityczna i społeczna ${ }^{25}$.

\section{Demokracja - autorytaryzm}

Określenie pozycji danego społeczeństwa na wyżej wymienionych trzech osiach pomiędzy skrajnymi wartościami służy ustaleniu jego miejsca na osi rozpościerającej się między demokracją a autorytaryzmem. Tym sposobem Jabłońskiemu udaje się uniknać dwóch problemów, przed którymi stoi klasyczna koncepcja. Po pierwsze, zastępuje sztywne klasyfikacje elastyczniejszą formą. Dzięki temu możliwe jest bardziej szczegółowe spojrzenie na kultury polityczne mimo mniejszej liczby zmiennych branych pod uwage. Po drugie, zostaje rozwiąany problem kultury obywatelskiej i określania warunków sprzyjających demokracji. Kultury polityczne w tym ujęciu moga być uplasowane bliżej lub dalej systemu demokratycznego.

Postawy, które służą demokracji, to: racjonalizacja konfliktu, indywidualizm oraz egalitaryzm. Autor zwraca uwagę, że warunkami dobrze działającego systemu demokratycznego sa przede wszystkim konkurencja polityczna oraz swobodne uczestnictwo $\mathrm{w}$ polityce. Aby te wartości mogły zostać urzeczywistnione, jednostki nie powinny być poddawane działaniom sztywnych norm identyfikacji grupowej ${ }^{26}$.

W teorii demokracja jest tutaj przedstawiona jako typ idealny. System ten określają nie tyle konieczne instytucjonalne rozwiązania, takie jak pluralizm polityczny, wolne wybory itp., ile przez

25 Ibidem, s. 185.

${ }^{26}$ Ibidem, s. 186. 
wyznawane przez członków społeczeństwa wartości. Demokracja staje się stopniowalna. Państwo może być mniej lub bardziej demokratyczne, nie musi być czystą demokracją czy autorytaryzmem. W praktyce jednak termin „kultura polityczna” został mocno ograniczony. Daje się go określić jako zbiór wartości wyznawanych przez członków społeczeństwa, które sprzyjaja demokracji lub autorytaryzmowi.

\section{Koncepcja Zbigniewa Bloka}

Koncepcja Zbigniewa Bloka, podobnie jak ta Jabłońskiego, stara się ująć kulturę polityczną bardziej dynamicznie aniżeli jej klasyczna wersja. W przeciwieństwie jednak do Jabłońskiego nie zamierza jej tak znaczacco redukować. Termin ten ma być możliwy do zastosowania w badaniach empirycznych, a jego znaczenie musi zasadniczo odbiegać od znaczeń terminów obecnych już w naukach o polityce. By sprostać temu zadaniu, nacisk położono na rzeczownik „kultura”. Autor zrywa z rozumieniem kultury politycznej jako relacji między postawami jednostek a instytucjami politycznymi, która ma charakter behawioralny, i umieszcza kulturę polityczną w sferze świadomościowej:

Kultura polityczna jest to ta część świadomości społecznej, zarówno grupowej, jak i jednostkowej, która jest zdolna wyeliminować, zmodyfikować bądź uporządkować zachowania polityczne oraz decyzje polityczne ${ }^{27}$.

Kultura polityczna to wytworzone społecznie i internalizowane przez jednostkę systemy norm, idei, wartości, sposobów myślenia i odczuwania odnoszące się do życia politycznego. Widać więc, że w tym ujęciu zmianie ulega samo myślenie o kulturze. Ma ona tutaj charakter opresyjny, podobny do tego, jaki proponują między innymi Zygmunt Freud czy Michel Foucault. Dla tego ostatniego kultura jest przestrzenia uJArzmiania ${ }^{28}$ jednostki. Według Bloka

\footnotetext{
${ }^{27}$ Z. Blok: Czynniki determinujace kulture polityczna..., s. 52.

${ }^{28}$ M. Foucault: Historia seksualności, przekład B. Baran, T. Komendant, K. Matuszewski, Wydawnictwo Czytelnik, Warszawa 2000, s. 59.
} 
zaś kultura polityczna będzie tą represyjną częścią kultury, która wskazuje jednostce:

1) jakie idee, wartości, normy ma podzielać;

2) jakie nawyki, tradycje i wzory ma preferować;

3) jakie ma być jej nastawienie do kwestii polityki;

4) czyj interes ma być przede wszystkim respektowany.

$\mathrm{Na}$ tej podstawie Blok buduje empiryczne modele kultur politycznych, które nie sa jednak prosta typizacja. Dla niego bowiem modele kultury politycznej to przestrzeń pomiędzy skrajnymi wartościami w odniesieniu do powyższych czterech aspektów ${ }^{29}$.

Warto zwrócić uwagę, że autor od początku konstruuje swoja koncepcję przede wszystkim jako narzędzie badawcze. Co więcej, pozostawia ją otwarta, budując jedynie jej trzon. Nie definiuje zatem, jakie wartości moga być brane pod uwagę $\mathrm{w}$ każdym $z$ tych czterech aspektów. Przykładowo: w kwestii idei, wartości i norm da się wyróżnić takie osie, jak indywidualizm - kolektywizm, wolność - równość, sprawiedliwość - niesprawiedliwośćc $\hat{c}^{30}$. W aspekcie nawyków, tradycji i wzorów można mówić o osiach: demokracja - totalitaryzm, tolerancja - nietolerancja, elityzm - egalitaryzm ${ }^{31}$. W zakresie emocji wobec faktów, zjawisk i procesów politycznych osiami moga być: zgoda - walka, patriotyzm - kosmopolityzm, fundamentalizm - nihilizm ${ }^{32}, z$ kolei dla oceny polityki i polityków takie np.: sprawiedliwe - niesprawiedliwe, efektywność - skuteczność, obiektywizm - uznaniowość ${ }^{33}$.

Wypada tu zauważyć, że proces badania kultury politycznej $\mathrm{w}$ prezentowanym ujęciu przebiega analogicznie jak w przypadku koncepcji Jabłońskiego: wyznaczaja ja punkty, które dana społeczność zajmuje na osi pomiędzy skrajnymi wartościami. Różnica jednak polega na tym, że Blok nie sprowadza wszystkich

\footnotetext{
${ }^{29}$ Z. Blok: Czynniki determinujace kulture polityczna..., s. 53.

${ }^{30}$ Ibidem, s. 62.

${ }^{31}$ Ibidem, s. 63.

${ }^{32}$ Ibidem, s. 65.

${ }^{33}$ Ibidem, s. 66.
} 
wyznaczników do miejsc na osi demokracja - autorytaryzm oraz nie tworzy także innych modeli typologicznych.

Nie wchodząc dokładnie $\mathrm{w}$ ten czysto praktycystyczny aspekt koncepcji Zbigniewa Bloka, należy podkreślić, że „kultura polityczna" jest pojęciem bardzo złożonym, które wymyka się prostej typizacji. Klasyfikacja bowiem nigdy nie pozwala dokładnie ująć rzeczywistości, zawsze znajdzie się taki jej element, który nie mieści się $\mathrm{w}$ zaproponowanym podziale. Blok zdaje sobie $z$ tego sprawę, dlatego na takie rozwiązania nie wskazuje, lecz próbuje ująć kulturę polityczna bardziej dynamicznie.

Powyższe trzy współczesne koncepcje kultury politycznej ukazuja, jak bardzo złożone jest to pojęcie i nastręczające wiele problemów. $Z$ jednej strony bowiem panuje zgoda co do tego, iż jest to termin użyteczny na gruncie nauk o polityce, $z$ drugiej zaś, że nie da się uniknąć jego wieloznaczności. Każdy z wyżej wymienionych autorów formułuje nie tylko inna jego definicję, ale także wyznacza odmienny zakres problemowy, na gruncie którego pojęcie to może funkcjonować. Definicja analizowanego terminu może się rozszerzać i zawężać względem klasycznej definicji, a także się zmieniać w zależności od tego, na co położy się większy nacisk: na kulturę czy na politykę. Warto jednak zauważyć, że pomiędzy tymi koncepcjami istnieja pewne punkty wspólne, jak np. zwrócenie uwagi (w mniejszym lub większym stopniu) na postawę jednostki. Można jednak ująć problem kultury politycznej z zupełnie innej perspektywy, traktując ją już nie jako narzędzie badawcze odnoszone do pragmatyki życia społecznego. Tę inną perspektywę uzyskuje się na gruncie filozofii polityki.

\section{Kultura polityczna w filozofii politycznej}

Jak stwierdzają Kościelniak i Wiśniewski, filozofów polityki interesuja nie fakty polityczne, ale raczej kontrfaktyczne ujęcia rzeczywistości politycznej, czyli to, co odnosić się będzie do zasad, 
ogólnych idei czy prawidłowości w świecie społecznym ${ }^{34}$. Badacze stawiaja sobie za cel skonstruowanie struktury pojęcia „kultury politycznej" na podstawie określenia zaproponowanego przez Almonda i Powella. Jak zostało na wstępie zaznaczone, definicja klasyczna wyróżnia następujące aspekty kultury politycznej: orientacje poznawcza, afektywną i oceniajaccą ${ }^{35}$. Kościelniak i Wiśniewski proponują ujęcie ich $z$ trochę innej strony, nazywając je odpowiednio: epistemicznym, emotywnym i moralnym elementem kultury politycznej.

W kontekście aspektu epistemologicznego, stanowiącego odpowiednik orientacji poznawczej, badacze zamiast o wiedzy będa mówić o poznaniu politycznym, który charakteryzuje się dwoma cechami: racjonalnością oraz dyskursywnością. Racjonalność oznacza to, że jednostki, mając wiedzę o świecie politycznym, oczekują, że działania polityczne będa dobierane tak, by jak najefektywniej osiagać cele polityczne. Można tutaj mówić o założeniu racjonalności działania systemu. Dyskursywność oznaczać tu będzie fakt, że jednostki sa w stanie na drodze racjonalnej debaty zmienić swoje poglądy polityczne ${ }^{36}$. Uogólniając, epistemiczny aspekt kultury to po prostu racje, dla których jednostki podejmują się uznać czy też odrzucić zasady działania instytucji politycznych. Racje te moga być dyskutowane i zmieniać się na drodze deliberacji.

W pewnej opozycji do epistemicznego aspektu kultury politycznej stoi aspekt emotywny, zakładający, że w kulturze politycznej jednostki nie tylko wyrażaja racje, ale także i emocje, które nie powstaja $\mathrm{w}$ wyniku dyskursu i nie musza mieć nic wspólnego $z$ racjonalnością. Będa to po prostu preferencje jednostek, które nie sa racjonalne. Nasze emocje czy preferencje dotyczace instytucji politycznych nie muszą wypływać $z$ naszej wiedzy o nich. W definicji politologicznej emocje świadczyły o poziomie naszego zaangażowania w kulturę polityczną. W ujęciu filozoficznym emo-

\footnotetext{
${ }^{34}$ C. Kościelniak, J. Wiśniewski: Kultura polityczna $w$ perspektywie filozofii politycznej, s. 33.

${ }^{35}$ Ibidem, s. 35.

${ }^{36}$ Ibidem, s. 36.
} 
tywny aspekt ujmowany jest dużo szerzej i odnosi się do indywidualnych preferencji jednostki ${ }^{37}$.

Ostatnim aspektem odpowiadajacym orientacji emotywnej u Almonda i Verby jest aspekt moralny kultury politycznej, rozumiany tutaj jako zespół zasad, których jednostka oczekuje od obiektów politycznych. Zasady te maja charakter transcedentny względem jednostki, czyli ich obowiazywanie nie stanowi następstwa subiektywnych opinii ${ }^{38}$.

Tak skonstruowana definicja pozwala badaczom na wyznaczenie dwóch możliwych podejść czy też dwóch punktów wyjścia w konstruowaniu kultury politycznej. Pierwsze to podejście indywidualistyczne, w którym wychodzi się od określenia cech konstytutywnych jednostki i na ich podstawie buduje sie taki model relacji, aby był zgodny $z$ celami i dążeniami jednostki. Na przykład Robert Nozick wychodzi od stanu natury i potrzeb jednostki (bezpieczeństwo, ochrona) i na tej podstawie konstruuje stosunki między nią a państwem ${ }^{39}$.

Drugim podejściem jest podejście holistyczne, które rozpoczyna się od określenia norm, zasad i praw. W tym modelu, ze względu na wyżej wymienione wartości transcendentne wobec jednostki, określa się stosunki, jakie maja panować miedzy instytucjami politycznymi a jednostkami. Przykładem takiego ujęcia może być koncepcja sprawiedliwości Johna Rawlsa ${ }^{40}$.

Filozoficzne ujęcie kultury politycznej, zaproponowane przez Kościelniaka i Wiśniewskiego, pozostaje w bardzo bliskiej łączności z klasyczna koncepcja politologiczną. Kultura polityczna staje się tutaj pewnym narzędziem do konstruowania teorii politycznej. Teorie te różnić się będą w zależności od tego, od którego aspektu wyjda (epistemicznego, afektywnego czy moralnego) i jak zostaną ułożone między nimi dalsze relacje. Należy jednak uwzględnić wszystkie trzy - dopiero to pozwala na skonstruowanie dobrej teorii.

\footnotetext{
37 Ibidem.

38 Ibidem, s. 37.

39 Ibidem, s. 39.

${ }^{40}$ Ibidem, s. 41.
} 


\section{Zakończenie}

Celem niniejszego artykułu nie było klarowne i wyczerpujące przedstawienie współczesnego rozumienia terminu „kultura polityczna”. To skrótowe ukazanie kilku współczesnych koncepcji miało na celu ukazanie, jak wieloznaczny jest to termin i jak różnie może być ujmowany zarówno w politologii, jak i w filozofii. Wychodzac od klasycznej definicji tego pojęcia, zaproponowanej przez Almonda i Powella, którzy powiązali je $z$ postawami jednostki wobec obiektów politycznych, różni badacze próbowali je albo zawęzić, albo rozszerzyć. Mimo znaczących różnic między wskazanymi w niniejszym tekście ujęciami wydaje się, że da się wykazać ich dwa punkty wspólne: 1) przekonanie, że mimo niedookreśloności termin ten może być użyteczny na polu nauki oraz 2) że powinna być to kategoria empirycznie weryfikowalna.

Trzeba jednak zaznaczyć, iż ta wieloznaczność, niedookreśloność nie jest specjalnie zaskakująca, bo przecież zarówno kultura, jak i polityka sa terminami wieloznacznymi. Czy jednak nie sprawia to, że termin „kultura polityczna” staje się coraz mniej użytecznym narzędziem? Co właściwie mamy na myśli, mówiąc o kulturze politycznej? Nie podejmę się odpowiedzi na te pytania. Być może ta niejednoznaczność jest $\mathrm{w}$ tym przypadku funkcjonalna. $\mathrm{W}$ ten sposób „kultura polityczna” staje sie pojęciem pozwalajacym na konstruowanie myśli odniesionej do wielu aspektów rzeczywistości politycznej. Różnie ujmowana, pozwala na wydobywanie nowych faktów czy odmiennych ujęć, a w konsekwencji rozszerza wiedzę o świecie. 